\title{
Thomas Raff
}

\section{Die gewöhnlichen Erhaltungskosten}

Verwendungsersatz und Nutzungszuordnung im Eigentümer-Besitzer-Verhältnis

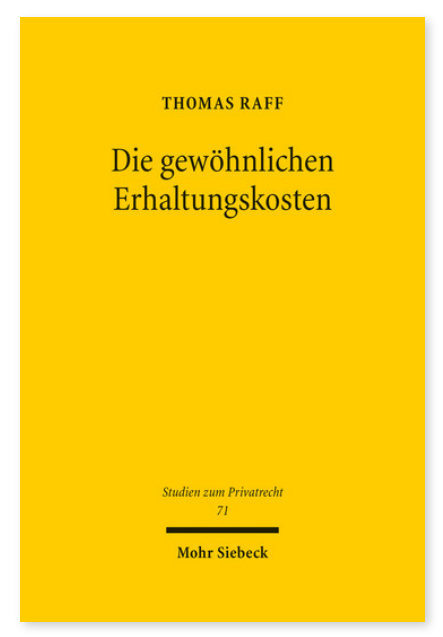

2017. XXVI, 569 Seiten. StudPriv 71

ISBN 978-3-16-155332-5

DOI 10.1628/978-3-16-155332-5

eBook PDF 139,00€

ISBN 978-3-16-154994-6

Leinen $139,00 €$
Ausgehend von §§ 994 Abs. 1 S. 2 und 995 S. 2 BGB untersucht Thomas Raff das Verhältnis von Verwendungen und Nutzungen im Eigentümer-Besitzer-Verhältnis. Die gewöhnlichen Erhaltungskosten erfüllen eine wichtige Funktion: Sie mitteln zwischen den Interessen des gutgläubigen Besitzers und dem Schutz des Eigentümers. Dass (ein Teil der) Nutzungen von Verwendungsersatzansprüchen abzuziehen ist, ist ein privatrechtliches Prinzip. Es lässt sich in Quellen des römischen Rechts und des 19. Jahrhunderts ebenso nachweisen wie im geltenden französischen, österreichischen und polnischen Recht. Die gefundenen Ergebnisse lassen Rückschlüsse auf das Eigentümer-Besitzer-Verhältnis insgesamt zu. Dieses kann mit dem Sacherhaltungs- und Sachverbesserungsprinzip erklärt werden und ist anderen Rückabwicklungsmechanismen wie dem Bereicherungsrecht oder der Geschäftsführung ohne Auftrag überlegen.

Thomas Raff Studium der Rechtswissenschaften in Heidelberg, Krakau und Paris; 2011 Erstes Staatsexamen; Referendariat am Landgericht Heidelberg; 2015 Zweites Staatsexamen; 2016 Promotion; seit 2016 Notarassessor in der Pfalz.

Jetzt bestellen:

https://mohrsiebeck.com/buch/die-gewoehnlichen-erhaltungskosten-9783161553325?no_cache=1 order@mohrsiebeck.com

Telefon: +49 (0)7071-923-17

Telefax: +49 (0)7071-51104 